\title{
Prevalence and Possible Risk Factor of Premarital Sexual Behaviour among Nepalese Adolescents
}

\section{Maginsh Dahal}

Nanjing Medical University

Raj Kumar Subedi

Bhaskar Medical College and Bhaskar General Hospital

\section{Sudip Khanal}

Pokhara University

\section{Anup Adhikari}

NDRI: Nepal Development Research Institute

\section{Manoj Sigdel}

Nepal Development Research Institute

Kushalata Baral

Pokhara University

\section{Raj Kumar Sangroula}

Buddha Institute of Technology

Cheng Xu ( $\square$ chengxu@njmu.edu.cn )

Nanjing Medical University

\section{Aihua Gu}

Nanjing Medical University

\section{Research}

Keywords: Adolescents, behaviour, premarital sex, sex education, Nepal

Posted Date: September 23rd, 2020

DOl: https://doi.org/10.21203/rs.3.rs-78183/v1

License: (a) (i) This work is licensed under a Creative Commons Attribution 4.0 International License.

Read Full License 


\section{Prevalence and possible risk factor of Premarital Sexual Behaviour among \\ 2 Nepalese Adolescents}

3

4 Maginsh Dahal $^{\text {a }}$, Raj Kumar Subedi ${ }^{\text {b }}$, Sudip Khanal ${ }^{\text {c }}$, Anup Adhikari ${ }^{\text {d }}$, Manoj Sigdel ${ }^{\text {, }}$,

5 Kushalata Baral ${ }^{\mathrm{c}}$, Raj Kumar Sangroula ${ }^{\mathrm{e}}$, Cheng $\mathrm{Xu}^{\mathrm{a}^{*}}$, Aihua $\mathrm{Gu}^{\mathrm{a}^{*}}$

6

$7{ }^{a}$ State Key Laboratory of Reproductive Medicine, School of Public Health, Nanjing Medical 8 University, Nanjing, China

$9 \quad \mathrm{~b}$ Bhaskar Tejshree Memorial Foundations, Nepal

$10{ }^{\mathrm{c}}$ Department of Public Health, Nobel College (Pokhara University), Sinamangal, Kathmandu, 11 Nepal

$12{ }^{\mathrm{d}}$ Nepal Family Development Foundations, Kupondole, Nepal

13 e Department of Public Health, Little Buddha College of Health Sciences, Kathmandu, Nepal

15 Running title: PSB in Nepalese adolescents

16

17 *\#Correspondence to:

18 Cheng $\mathrm{Xu}$, School of Public Health, Nanjing Medical University, 101 Longmian Avenue, 19 Nanjing 211166, China.Email: chengxu@njmu.edu.cn

20 Aihua Gu, School of Public Health, Nanjing Medical University, 101 Longmian Avenue, 21 Nanjing 211166, China. Email: aihuagu@ njmu.edu.cn 
Background: To determine the prevalence of premarital sex and its risk factors in Nepal.

26 Methods: A cross-sectional study was carried out among adolescents in Nepal. A self27 administered questionnaire was used to collect information from 6,147 unmarried adolescents.

28 Random sampling by using a lottery method was applied to select 20 colleges from all three

29 districts. All the students who were studying at those colleges were enrolled in the study. Simple 30 and multivariate logistic regression analyses were carried out to analyse the associations of risk 31 factors and premarital sex.

32 Results: The prevalence of premarital sex was 38.1\%. Male students were more likely to engage 33 in premarital sex (adjusted odds ratio $[\mathrm{AOR}]=2.04$, confidence interval $[\mathrm{CI}]=1.76-2.36$ ) than 34 female students. Alcohol consumption ( $\mathrm{AOR}=1.26, \mathrm{CI}=1.08-1.47)$, smoking (AOR=1.69, $35 \mathrm{CI}=1.41-2.02)$, drug use $(\mathrm{AOR}=1.85, \mathrm{CI}=1.23-2.83)$, going to night clubs $(\mathrm{AOR}=1.46, \mathrm{CI}=1.24-$ 1.70), clothing style of girls $\mathrm{AOR}=1.35, \mathrm{CI}=1.15-1.58)$, clothing style of boys ( $\mathrm{AOR}=3.51$, $37 \mathrm{CI}=2.74-4.53)$, and unmarried friends having sex $(\mathrm{AOR}=1.51, \mathrm{CI}=1.31-1.73)$ were found to be 38 major influencing factors for premarital sex. Moreover, students who had never received sex 39 education were 2.92 times more likely to engage in premarital sex $(\mathrm{CI}=2.22-3.85)$ than those 40 who had previously received sex education.

41 Conclusions: We found several risk factors associated with premarital sex in Nepal. Preventing 42 premarital sex may require the promotion of sex education.

44 Keywords: Adolescents, behaviour, premarital sex, sex education, Nepal 


\section{Plain English summary}

47 The study is conducted in Nepal because of the similar socio economic background and perceptions this study reflects the status of premarital sex and its factors among adolescents of entire South Asian countries. Pre-marital sex among adolescents has been increasing globally, and is being more acceptable. This study will help as baseline information for the policy maker and other government workers as the clear picture of the current scenario of the sexual health among adolescents in Nepal.

\section{Introduction}

55 Premarital sex is defined as any and all forms of sex before marriage (1). Youth risk behaviour surveillance in 2013 revealed that $46 \%$ of the students in the USA had engaged in sexual intercourse. The prevalence of ever having sex was highest among black males, followed by Hispanic students. Approximately $14 \%$ of the black students had sexual intercourse before the age of 13 (1). In 2016, the prevalence of premarital sex was 27.6\% among secondary school students in Nigeria (2). Moreover, the prevalence of premarital sex was $39.7 \%$ among young people in Ethiopia (3). Results from developing countries such as Indonesia, Nepal, Thailand, and the Philippines suggest that risky behaviours such as premarital sex and substance abuse are increasing among adolescents (4). Premarital sex may result in sexually transmitted infections (STIs), including human immunodeficiency virus (HIV). Particularly, adolescent girls may experience an unwanted pregnancy and seek abortion, which can cause various complications, including death. In addition, girls may drop out of school to raise their children, and in most cases, they become economically dependent upon their parents (5). Girls also may experience the additional burdens of premarital child bearing and rearing (6). The reasons for premarital sex among adolescents are complex and may include easy access to various sexual content in movies as well as internet-based pornography. Similarly, adolescents are also likely to experiment with risky behaviours because of physiological and emotional transitions during this stage of development (7). Addressing the burden of premarital sexual behaviour, along with focusing on intervention research, can help reduce the risks associated with it. 
Previous studies on kindred area suggest that individual, family and peer factors such as age; rural family residence; alcohol consumption; smoking habits; attitude towards virginity; having a boyfriend; peers' sexual behaviour, including having friends with dating experience; having close unmarried friends engaging in premarital sex; discussing sexual matters with friends; going to night clubs; viewing pornographic materials; parents education; and parental status (whether raised by a single parent or both parents) had a strong influence on premarital sex among higher secondary level students (8-11). Notably, household, community and country differences are also considered to be predictors of the risk of premarital sex (12). However, many factors are still unknown, especially in underdeveloped areas.

Previous reports on premarital sex in Nepal show that one-third (32\%) of the Nepalese population is aged 10-24 years, and this age group has the greatest need for sexual and reproductive health services (13). As in other Asian countries, premarital sex is taboo in Nepal, discouraging sexual contact between young unmarried males and females (10). Due to the increase in late marriage, decrease in family influence on adolescents, and increase in urbanization as well as exposure to media, globalization and modernization, sexual and reproductive behaviour among adolescents have been changing (10, 11). Although sufficient information and formal education about sexual and reproductive health are provided, the rate of premarital sex has been increasing worldwide (14). An average of $29 \%$ of boys and $23 \%$ of girls are sexually active and engage in premarital sex in many parts of the world (15).

Over the past few decades, premarital sex among adolescents has increased globally, especially in the Western world, and it is becoming increasingly acceptable $(16,17)$. Some studies have shown that premarital sex is increasing in Nepal. A study conducted in colleges in Kathmandu Valley showed that almost two-fifths of the students had engaged in premarital sex (10). However, the study did not explore possible lifestyle factors and was conducted with a small sample size. Based on the above, this study investigated more than 6,147 adolescents aged 17-19 years in three regions by random stratification; it was expected that risky lifestyles would be related to premarital sexual behaviour, providing a theoretical basis for subsequent universal education and interventions. Therefore, we performed a study to assess the prevalence of and risk factors for premarital sex in Nepal. 


\section{Methods}

107 An institution-based quantitative survey was conducted among 6,147 students aged 17, 18, and 10819 years from colleges in Kathmandu Valley after written informed consent was obtained. 109 Kathmandu Valley was selected as the study area because it comprises three districts 110 (Kathmandu, Bhaktapur, and Lalitpur). It is also the capital of Nepal. The majority of students 111 come to this area from different parts of the country after completion of secondary level 112 education to attend higher education institutions. Thus, Kathmandu was selected as the study site 113 so that we could obtain a sample of adolescents from all regions of the country.

\section{Ethical aspects}

116 The study was approved by the ethical review board of the Nepal Health Research Council. 117 Confidentiality was assured, and no personal information of students, as well as colleges, was 118 disclosed without the permission of the respondents. A specific code was assigned to each 119 college and its students, and they were asked not to include their name or the name of the 120 institution on their questionnaire. The sample colleges were not publicly disclosed, so the 121 possibility of anyone outside the core research team tracing the reported sexual behaviour of 122 respondents and their associated college was impossible.

\section{Sample size and sampling}

125 We used the following formula to calculate the sample size:

$$
\mathrm{n}=\left(\frac{\mathrm{Z}_{\alpha}}{\mathrm{E}}\right)^{2} \mathrm{PQ}
$$

126 where,

$127 \mathrm{n}=$ required sample size

$128 \alpha=5 \%$ (desired level of significance)

$129 Z_{\alpha}=Z_{0.05}=1.96$ (from the normal table)

$130 \mathrm{P}=18.3 \sim 20 \%$, i.e., 0.2 (prevalence of premarital sex) (8).

$131 \mathrm{Q}=1-\mathrm{P}=0.8$

$132 \mathrm{E}=0.01$ (desired error) 


$$
n=\left(\frac{1.96}{0.01}\right)^{2} \times 0.20 \times 0.80=6146.56
$$

133 The minimum sample size required was 6,147 .

134 Random sampling by using a lottery method was applied to select 20 colleges from all three 135 districts. The list of all public and private colleges from the Nepal Education Board was 136 considered the sample frame. All the students who were studying at those colleges were enrolled 137 in the study.

\section{Data collection and analysis}

140 The data were collected using a structured self-administered questionnaire prepared in the local 141 language (Nepali). The questionnaire consisted of questions about sociodemographic 142 information, risk behaviour, sexual behaviour and knowledge about health consequences. 143 Questions related to the knowledge and practice of premarital sex were asked to obtain research 144 data. The participants were asked, "Do you have a boyfriend/girlfriend?", "Have you ever been 145 involved in sexual activities?", "Do you smoke/consume alcohol/use drugs/go to night clubs?”. 146 Additionally, major questions related to their family relationships and pocket expenses were 147 asked. If a participant answered "Yes", he or she was considered to have had premarital sex. The 148 outcome was thus converted to a dichotomous variable. Approximately 30 minutes was provided 149 to complete the questionnaire. The validity of the questionnaires was verified by pretesting 400 150 samples before actual data collection. All the students who were unmarried and willing to 151 participate were eligible to participate in the study. The information of all the students at each 152 college was collected at the same time so that information bias was minimal. Due to the sensitive 153 nature of the study, the students were asked to sit on separate benches (one student per bench) 154 during the break time. Written informed consent was obtained from the students prior to 155 administering the questionnaire and information sheet. Students were told to keep their 156 completed questionnaires and consent forms together and individually place them in a specific 157 location inside the classroom before leaving the classroom so that the identity of the respondents 158 would not be revealed to survey enumerators. 
The data analysis was carried out using descriptive statistics and inferential statistics. Bivariate statistics including chi-square tests and t-tests were computed to evaluate the differences in sociodemographic characteristics among adolescents who engaged in or did not engage in premarital sex. A multivariate analysis was carried out using logistic regression with the following formula (18). A P-value of 0.05 was considered statistically significant.

$$
\ln \left(\frac{p}{1-p}\right)=\alpha+\beta_{1} x_{1}+\beta_{2} x_{2} \ldots \ldots .+\beta_{p} x_{p}
$$

$\mathrm{p}_{(\mathrm{y} / \mathrm{x})}=\frac{\exp \left(\alpha+\beta_{1} \mathrm{x}_{1}+\beta_{2} \mathrm{x}_{2} \ldots \ldots+\beta_{\mathrm{p}} \mathrm{x}_{\mathrm{p}}\right)}{1+\exp \left(\alpha+\beta_{1} \mathrm{x}_{1}+\beta_{2} \mathrm{x}_{2} \ldots \ldots+\beta_{\mathrm{p}} \mathrm{x}_{\mathrm{p}}\right)}$

Odds ratio: $\mathrm{OR}=\exp ^{\beta}$

Confidence interval: $\exp \left[\widehat{\beta} \pm \mathrm{Z}_{1-\alpha / 2} \times \widehat{\mathrm{SE}}(\widehat{\beta})\right]$

The collected data were entered into Epi-data version 3.2 and then extracted and imported into Excel 2019. The final data were analysed with the help of R-studio (version 1.2.5033).

\section{Results}

Table 1 shows the distributions of sociodemographic variables and the associations between sociodemographic variables and premarital sex. In our study, 51.4\% of the respondents were male, and $48.6 \%$ of the respondents were female. The mean $\pm \mathrm{SD}$ of the age of the respondents was $17.51 \pm 0.69$. The highest percentages of adolescents were from the Humanities department (43.7\%), followed by the science (38.4\%) and management (35.0\%) departments. Furthermore, the proportion (59.1\%) of students who had engaged in sex at the age of 19 years was larger than those of students who had engaged in sex at 17 and 18 years. Regarding religion, Muslim and other $(44.1 \%)$ religious groups had the highest rate of premarital sex, followed by the Hindu (38.6\%), Buddhist (35.4\%), and Christian (30.1\%) religious groups. The Newari ethic group (44.3\%) had engaged in premarital sex more frequently than the Brahmin/Chhetri, Dalit/Janajati and other ethnic groups. In addition, respondents who lived without family (48.1\%), e.g., living in a hostel, alone or with friends, had a higher rate of premarital sex than those who lived with family (35.2\%). Respondents belonging to a nuclear family (38.5\%) had a higher rate of 
premarital sex than those belonging to a extended family (36.8\%). Nearly 45 out of 100 respondents consumed alcohol, and 58.7\% were smokers.

Table 2 shows the multivariate logistic regression analysis results, indicating that males were more likely to have engaged in premarital sex $[\mathrm{AOR}=2.04,95 \% \mathrm{CI}(1.76,2.36)]$ than females. Similarly, the respondents belonging to the humanities department and science department had 1.56 times [95\% CI $(1.20,2.03)]$ and 1.02 times [95\% CI $(0.87,1.20)]$ higher rates of premarital sex, respectively, than those from the management department. Respondents aged 19 years and 18 years were 2.07 times [95\% CI $(1.69,2.54)]$ and 1.34 times [AOR=1.34, 95\% CI $(1.16,1.54)]$ more likely to have engaged in premarital sex, respectively, than those aged 17 years. Moreover, Muslim, Hindu and Buddhist respondents were 1.70 times [95\% CI $(1.00,2.92)], 1.98$ times [AOR $=1.98,95 \% \mathrm{CI}(1.38,2.87)]$ and 1.73 times $[95 \% \mathrm{CI}(1.15,2.61)]$ more likely to have engaged premarital sex, respectively, than Christian respondents. The Brahmin/Chhetri and Newar ethnic groups were 1.13 times [95\% CI $(0.95,1.35)]$ and 1.54 times [95\% CI $(1.25,1.91)]$ more likely to have engaged in premarital sex, respectively, than the Dalits/Janajatis ethnic groups. Those who did not live with family were 1.16 times $[95 \% \mathrm{CI}(1.00,1.35)]$ more likely to have engaged in premarital sex than to those who lived with family. The respondents with monthly expenditures $>3,000 \mathrm{NRs}$ were 1.40 times $[95 \% \mathrm{CI}(1.23,1.59)]$ more likely to have engaged in premarital sex than those with monthly expenditures $\leq 3,000$ NRs.

The respondents who were very satisfied in their relationship with their parents were 1.6 times (95\% CI: 1.23-2.08) more likely to have engaged in premarital sex than those who were only satisfied. Respondents who consumed alcohol were 1.26 [AOR=1.26, 95\% CI (1.08-1.472)] times more likely to have engaged in premarital sex than those who did not consume alcohol. Similarly, respondents who were smokers were 1.69 [95\% CI $(1.41,2.02)]$ times more likely to have engaged in premarital sex than non-smokers. Those who used drugs and went to night clubs were 1.85 [95\% CI $(1.23,2.83)]$ and 1.46 [95\% CI $(1.24,1.70)]$ times more likely to have engaged in premarital sex than those who did not use drugs and did not go to night clubs. Respondents who preferred sexy clothing styles of girls and boys were 1.35 times [95\% CI (1.15, $1.58)]$ and 3.51 times [95\% CI $(2.74,4.53)]$ more likely to have engaged in premarital sex than those who preferred the simple clothing style of girls and boys, respectively. Those respondents who had unmarried friends who engaged in premarital sex were 1.51 times [95\% CI $(1.31,1.73)$ ] 
more likely to have engaged in premarital sex than those without unmarried friends who engaged in premarital sex, and the respondents who never received sex education were 2.92 times [95\% CI $(2.22,3.85)]$ more likely to have engaged in premarital sex than those who received sex education. However, the respondents with knowledge about premarital sex were 2.50 times [95\% CI $(2.08,3.02)]$ more likely to have engaged in premarital sex than those who did not know about premarital sex.

\section{Discussion}

This study identified the situation and possible influencing factors of premarital sex in Nepal. Through our research, we attempted to analyse a large sample size of adolescents from different parts of the country to increase the generalizability of our findings. The study results showed that there was a significant self-reported prevalence of premarital sex despite Nepal being a lowincome and highly religious country. In the multivariate analysis, students who smoked, consumed alcohol and used drugs were more likely to have engaged in premarital sex than those who did not, while receiving sex education was found to be a major protective factor.

This study showed that the prevalence of premarital sex among adolescents was $38.1 \%$. The findings of the Nepal Demographic and Health Survey showed that $25 \%$ of unmarried men and $1 \%$ of unmarried women have had premarital sex (13). An institution-based cross-sectional study conducted in Nepal showed that $24.6 \%$ of the respondents had engaged in premarital sex (11). Another study conducted in India reported that 16-18\% of the respondents had engaged in premarital sex (19). The prevalence found in our study is high compared to those in these studies. This might be because adolescents today are more accepting of premarital sex than they were in previous years and because the strict confidentiality measures we took enabled respondents to share sensitive information. However, it is important to note that premarital sex is still a social taboo in Nepal, so there might be underreporting, with the true numbers being even higher than those reported here.

Our study found that adolescents aged 18 and 19 years were more likely to have engaged in premarital sex than those aged 17 years. A study conducted in Nepal showed a significant association between age and premarital sex $\left(\chi^{2}=7.290\right.$, p-value: 0.007) (20). In Ethiopia, it was found that adolescents aged 18 years or more were more likely to have had premarital sex than 
those aged less than 18 years (AOR: 3.8, 95\% CI 1.6-9.2) (21). Another Ethiopia-based study showed that the odds of premarital sex increased by $33 \%$ with age (AOR: $1.33,95 \%$ CI 1.05-1.7, p-value: <0.01) (8). Although these studies did not have similar cut-off points for age, they indicate that premarital sex becomes more common with age, which aligns with our findings. This might be because as adolescents age, they start exploring the changes in their body through the use of books, online media and peer circles, and the influences these resources have might make them more open to premarital sex.

This study identified that males were more likely to have engaged in premarital sex than females. A study conducted in Nepal showed that males were 1.64 times more likely to engage in premarital sex than females (Yates correlation $\chi^{2}=38.5$, risk ratio: 1.64) (11). In Malaysia, a study showed that adolescent males were three times more likely to engage in premarital sex (AOR: 2.7 95\% CI 1.39-5.25, p-value: 0.003) than adolescent females (22). In Ethiopia, a study showed that adolescent males were 1.88 times more likely to engage in premarital sex than adolescent females (AOR: 1.88 95\% CI 1.21-2.93, p-value: <0.0 1) (15). These studies mirror the findings of our research. This is likely because Nepal, as a patriarchal country, tolerates some freedom for males to engage in sexual activity but greatly values female virginity, meaning females are less willing to engage in premarital sex than males. Another plausible explanation might be the tendency among girls to underreport information about their private sex life (23, 24).

This study showed that adolescents who were not living with family were 1.16 times more likely to have engaged in premarital sex than those living with family. A World Health Organization (WHO) report (25) and a United Nations Population Fund (UNFPA) review (26) identified living with parents as a key protective factor against premarital sex. In Cambodia, a study showed that adolescents who were living away from their families were more likely to engage in premarital sex than those living with their families (OR: $1.8095 \%$ CI 1.28-2.59, p-value: <0.001) (27). An Ethiopia-based study identified that adolescents who did not live with their parents were six times more likely to engage in premarital sex than those who did live with their parents (AOR: 6.6 95\% CI 1.9-23.7, p-value: <0.05) (21). These results are consistent with our study findings. This is likely because adolescents who do not live with their parents have more independence 
277 and less parental monitoring than those who live with their parents, giving them more 278 opportunities and freedom to engage in premarital sex.

279 In our study, it was found that respondents whose monthly pocket expenditures were $>3,000$ 280 were more likely to have engaged in premarital sex than those whose pocket expenditures were $\leq$ 281 3,000. A study conducted in India identified that adolescents who had more spending money 282 were more likely to engage in premarital sex than those with less spending money (AOR: 2.13 $28395 \%$ CI 0.99-4.62) (28). In Ethiopia, a study found that college students who were given 284 spending money were more likely to engage in premarital sex than those who were not (AOR: 285 2.2 95\% CI 1.14-4.05) (9). Another Ethiopia-based study also reported that providing spending 286 money significantly increased the chance of engaging in premarital sex (AOR: 3.07 95\% CI 287 1.96-4.81) (15). These findings align with our study results. This is likely because adolescents 288 who receive spending money are financially able to date girls, attend parties, consume alcohol, 289 or buy pornography, all of which increase the likelihood of premarital sex. In addition, 290 adolescents who receive spending money might even pay for sex.

291 In our study, substance use was significantly associated with the practice of premarital sex. 292 Adolescents who consumed alcohol, smoked cigarettes, or used drugs were more likely to have 293 engaged in premarital sex than those who did not. The findings of a WHO report identified 294 alcohol use and cigarette smoking among males and the use of drugs in males and females as key 295 risk factors for premarital sex among adolescents (25). In Malaysia, it was found that adolescents 296 who consumed alcohol (AOR: 2.7 95\% CI 1.99-3.66), smoked (AOR: 4.1 95\% CI 3.06-5.56) or used drugs such as marijuana (AOR: 10.6 95\% CI 6.99-16.13), heroin (AOR: 17.5 95\% CI 8.5535.71) or intravenous drugs (AOR: 15.6 95\% CI 7.58-32.26) were more likely to engage in premarital sex than those who did not (29). Another study conducted in Cambodia reported that unmarried adolescents who used alcohol (male: AOR=6.2 95\% CI 1.9-20.2, female: AOR= 3.7 95\% CI 1.5-8.7) or drugs (male: $\mathrm{AOR}=3.095 \%$ CI 2.0-4.4, female: AOR= 5.8 95\% CI 1.5-22.0) were more likely to be engaged in sexual behaviours than those who did not (30). These findings align with our study results. This might be because substance use decreases self-control and 304 rational thinking ability among adolescents, leading them to engage in activities that they might 305 otherwise hesitate to do. 
This study showed that adolescents who had unmarried friends who had sex were more likely to have engaged in premarital sex. The Army Welfare Housing Organisation (AWHO) report identified that having friends who have had sex was a key risk factor for premarital sex among adolescents (25). A Nepal-based study showed that respondents whose close unmarried friends had engaged in sex were nine times more likely to engage in premarital sex (OR: 9.2, p-value: $<0.001$ ) (10). In Singapore, a study showed that adolescent males (UOR: $5.5495 \%$ CI 3.60-8.51, p-value: <0.001) as well as females (UOR: 6.47 95\% CI 4.15-10.08, p-value: <0.001) who perceived that one or more of their friends had engaged in sex were more likely to engage in premarital sex (7). These findings are consistent with our study results. This might be because of the substantial influence peers have in an adolescent's life. The constant need among adolescents to fit in and the desire to experience what a peer has already experienced might increase an adolescent's likelihood of having premarital sex.

This study found that adolescents who had heard or had knowledge about premarital sex were more likely to have engaged in premarital sex than their counterparts. In India, a study found that extensive knowledge about sexuality protected adolescent males from premarital sex (OR: 0.43 95\% CI 0.18-0.98) (28). A study conducted in Ethiopia found that adolescents who had exposure to reproductive health information were less likely to have premarital sex than those who did not have exposure (AOR: 0.995, 95\% CI 0.988-1.012) (31). These findings contrast with our study results, but the difference could be explained by the source of the knowledge. It may possible that the majority of the adolescents in our study obtained their knowledge from peers. There is documented evidence indicating that discussing reproductive health $(\mathrm{RH})$ issues with friends is a risk factor for premarital sex $(32,33)$. This further validates the need for a strong formal sex education delivery system in Nepal.

Our study found that adolescents who had not received sex education were three times more likely to have engaged in premarital sex than those who had received sex education. A UNFPA report indicated that adolescents who received appropriate comprehensive sex education programmes were more likely to delay their sexual debut than those who did not receive appropriate education (34). In Uganda, a study that surveyed primary schools before and after a two-year educational intervention reported a higher risk ratio for sexual activity before the intervention in both males (risk ratio: 2.45 , p-value: 0.001 ) and females (risk ratio: 1.76, p-value: 
0.001) than after the intervention (35). A study conducted in India recommended the introduction of sex education in primary schools to ensure safe sexual behaviour among adolescents (36). These studies align with the findings of our study. This is likely because adolescents who do not receive sex education have very few opportunities to discuss their RH queries, and they are likely to discuss RH with peers who have incomplete knowledge, purchase pornography or are involved in paid sex, thus preventing them from making healthy decisions about their sex life.

There are some limitations in our study. First, the study was cross-sectional in nature, and a causal relationship cannot be established between the variables. Due to the sensitive nature of the study, the information regarding premarital sex, number of partners and age at first intercourse may be affected by reporting or information bias. Additionally, our estimation of prevalence was based on self-reported data from adolescents. Finally, we could not examine all the dimensions and risk factors for premarital sexual activities because of time limitations. Further research is required in the future to examine other factors that may help to understand the complex risk factors for premarital sex. With all these limitations in mind, we conducted our study to achieve the greatest possible validity and reliability.

\section{Conclusion}

This study revealed that students with a high family income and access to spending money are more likely to engage in premarital sex. The risk increases when parents are uneducated and when students do not live with their families. Peer influence and substance use were also strong determinants of premarital sex. Sex education was a strong protective factor. Thus, preventing premarital sex requires the promotion of sex education along with family and peer interventions.

\section{Acknowledgements}

Authors would like to acknowledge all the colleges as well as students who participated for the study on volunteer basis.

\section{Abbreviations}

AOR: Adjusted Odd's Ratio

CI: Confidence Interval 
HIV: Human Immune Deficiency Virus

367 NDHS: Nepal Demographic Health Survey

368 NHRC: Nepal Health Research Council

369 OR: Odd's Ratio

370 RR: Risk Ratio

371 SD: Standard Deviation

372 STI/D: Sexually Transmitted Infections/Diseases

373 UOR: Unadjusted Odd's Ratio

374 UNFPA: United Nations Population Funds

375 USA: United States of America

376 WHO: World Health Organizations

\section{Authors' contributions}

$378 \mathrm{MD}, \mathrm{AG}$ and RKS designed and parametrized the mathematical model, conducted the analyses,

379 and wrote the first draft of the article. CX, SK, AA and MS supported the model

380 parameterization, conducted the statistical analyses, and participated in the drafting of the article.

$381 \mathrm{~KB}$ and RKS conceived and led the design of the study and model, analyses, and drafting of the

382 article. MD, CX and AG revised the manuscript. All authors have read and approved the final

383 article.

385 Funding

386 This research did not receive any specific grant from funding agencies in the public, commercial, 387 or not-for-profit sectors.

\section{$389 \quad$ Availability of data and materials}

390 This manuscript's data will not be deposited because of sensitive nature of the study.

\section{Ethics approval and consent to participate}

393 The study was approved by the ethical review board of the Nepal Health Research Council.

394 Participants provided written informed consent and adolescents provided written assent. 


\section{Consent for publication}

Not applicable.

\section{Competing interests}

400 The authors declare that they have no known competing personal interests that could have 401 appeared to influence the work reported in this paper.

\section{References}

1. Kann L KS, Shanklin SL, Flint KH, Hawkins J, Harris WA, Lowry R, Olsen EO, McManus T, Chyen D, Whittle L. . Youth risk behavior surveillance-United States, 2013. CDC. 2014;63(4):1-68.

2. Chihurumnanya A, Lawrence U, Benedict N, Uche D, Nnenna A. Premarital Sex, Safer Sex and Factors Influencing Premarital Sex Practices Among Senior Secondary School Students in Ebonyi Local Government Area of Ebonyi State Nigeria. J Community Med Public Health Care. 2016;3:012. 3. Hurissa B, Tebeje B, Megersa H. Prevalence of pre-marital sexual practices and associated factors among Jimma teacher training college students in Jimma Town, South West Shoa Zone, Oromiya Region, Ethiopia-2013. J Women's Health Care. 2014;4(221):2167-0420.1000221. 4. Choe M, Hatmadji H, Podhisita C, Raymundo C, Thapa S. M.K. Choe, S.H. Hatmadji, C. Podhisita, C..M. Raymundo, and S. Thapa. Substance use and premarital sex among adolescents in Indonesia, Nepal, Philippines, and Thailand. Asia-Pacific Population Journal 19(1):5-26, 2004. 2018.

$4165 . \quad$ Taye A, Asmare I. Prevalence of Premarital Sexual Practice and Associated Factors among Adolescents of Jimma Preparatory School Oromia Region, South West Ethiopia. Journal of Nursing \& Care. 2016;05.

6. Mensch BS, Clark WH, Lloyd CB, Erulkar AS. Premarital sex, schoolgirl pregnancy, and school quality in rural Kenya. Studies in family planning. 2001:285-301.

7. Wong ML, Chan RK, Koh D, Tan HH, Lim FS, Emmanuel S, et al. Premarital sexual intercourse among adolescents in an Asian country: multilevel ecological factors. Pediatrics. 2009;124(1):e44-52.

8. Emebet T, Debebe S, Daka D. Prevalence, associated risk factors and consequences of premarital sex among female students in Aletawondo High School, Sidama Zone, Ethiopia. Journal of Public Health and Epidemiology. 2014;6:216-22.

9. Fekecha B, Tebeje B, Megersa H. Prevalence of Pre-marital Sexual Practices and Associated Factors among Jimma Teacher Training College Students in Jimma Town, South West Shoa Zone, Oromiya Region, Ethiopia-2013 Bekana Fekecha Hurissa*, Bosena Tebeje and Hirut Megersa' Jimma University, South West, Ethiopia. J Women's Health Care. 2014;4.

10. Adhikari R, Tamang J. Premarital Sexual Behavior among male college students of Kathmandu, Nepal. BMC Public Health. 2009;9(1):241.

11. Adhikari N, Adhikari S. Attitude towards Premarital Sex among Higher Secondary Students in Pokhara Sub-Metropolitan City. Journal of Community Medicine \& Health Education. 2017;07.

12. Chiao C. Community context and the prevalence of premarital sex among young women in Kenya and the Philippines: Trends and differences from 1993 to 2003. Health \& place. 2010;16(3):512-

43622.

437 13. The world bank. Nepal-Demographic and Health Survey 2016. The world bank; 2016. 
14. Arega WL, Zewale TA, Bogale KA. Premarital sexual practice and associated factors among high school youths in Debretabor town, South Gondar zone, North West Ethiopia, 2017. BMC Research $440 \quad$ Notes. 2019;12(1):314.

441 15. Behulu GK, Anteneh KT, Aynalem GL. Premarital sexual intercourse and associated factors west Ethiopia, 2017. BMC Research Notes. 2019;12(1):95.

16. Noroozi M, Taleghani F, Merghati-Khoei ES, Tavakoli M, Gholami A. Premarital sexual relationships: Explanation of the actions and functions of family. Iranian journal of nursing and midwifery research. 2014;19(4):424-31.

17. Chen AC-C, Neilands TB, Chan S-M, Lightfoot M. Contextual influence of Taiwanese adolescents' sexual attitudes and behavioral intent. Nursing \& Health Sciences. 2016;18(3):355-61.

18. David W. Hosmer J, Stanley Lemeshow, and Rodney X. Sturdivant. Applied Logistic Regression: John Wiley \& Sons, Inc.; 2013. 35-54 p.

19. Alexander M, Garda L, Kanade S, Jejeebhoy S, Ganatra B. Correlates of premarital relationships among unmarried youth in Pune district, Maharashtra, India. Int Fam Plan Perspect. 2007;33(4):150-9.

20. Basel P. Premarital sex behaviors among college youths of Kathmandu, Nepal. Kathmandu University medical journal. 2013;11(1):27-31.

21. Abate G, Tessema F, Girma A. Premarital sexual practice and associated factors among preparatory school students in Jimma town, Oromia region, South West Ethiopia. J of Bio, Agri and Healthcare. 2016;6(15).

22. Nawi AM, Roslan D, Idris IB, Hod R. Bullying and truancy: predictors to sexual practices among school-going adolescents in Malaysia - a cross-sectional study. Med J Malaysia. 2017;72(5):298-305.

23. Joshi B, Chauhan S. Determinants of youth sexual behaviour: program implications for India. Eastern Journal of Medicine. 2011;16(2):113.

24. Kreager DA, Staff J. The sexual double standard and adolescent peer acceptance. Social psychology quarterly. 2009;72(2):143-64.

25. Organization WH. Risk and protective factors affecting adolescent reproductive health in developing countries. 2005.

26. UNFPA. Sexual and reproductive health of unmarried young people in Asia and the Pacific: Review of knowledge, Behaviours and Practice. 2016.

27. Mai V, Kittisuksathit S. Factors influencing pre-marital sexual intercourse among unmarried young individuals in Cambodia. Makara Journal of Health Research. 2019;23(3):4.

28. Abraham L, Kumar KA. Sexual experiences and their correlates among college students in Mumbai City, India. International family planning perspectives. 1999:139-52.

29. Lee LK, Chen PC, Lee KK, Kaur J. Premarital sexual intercourse among adolescents in Malaysia: a cross-sectional Malaysian school survey. Singapore Med J. 2006;47(6):476-81.

30. Yi S, Tuot S, Yung K, Kim S, Chhea C, Saphonn V. Factors associated with risky sexual behavior among unmarried most-at-risk young people in Cambodia. 2014.

31. Sorato M, Belijo Z. Magnitude and Predictors of Premarital Sexual Practice among Unmarried Undergraduate Students, at Arba Minch University, Ethiopia, 2015. Int J Reprod Fertil Sex Health. 2017;4(2):95-104.

32. Magnani RJ, Karim AM, Weiss LA, Bond KC, Lemba M, Morgan GT. Reproductive health risk and protective factors among youth in Lusaka, Zambia. Journal of Adolescent Health. 2002;30(1):76-86.

33. Meekers D, Calves A-E. Gender differentials in adolescent sexual activity and reproductive health risks in Cameroon. African Journal of Reproductive Health. 1999;3(2):51-67.

34. UNFPA $U$. The evaluation of comprehensive sexuality education programmes: $A$ focus on the gender and empowerment outcomes. United Nations Population Fund New York, NY; 2015. 
485 35. Shuey DA, Babishangire BB, Omiat S, Bagarukayo $\mathrm{H}$. Increased sexual abstinence among in486 school adolescents as a result of school health education in Soroti district, Uganda. Health Education 487 Research. 1999;14(3):411-9.

488 36. Kumar R, Goyal A, Singh P, Bhardwaj A, Mittal A, Yadav SS. Knowledge attitude and perception 489 of sex education among school going adolescents in Ambala district, Haryana, India: a cross-sectional 490 study. Journal of clinical and diagnostic research: JCDR. 2017;11(3):LC01. 